\title{
Effects of intermittent microwave drying conditions on characteristics and physical properties of beetroots
}

\author{
Yan Liu' ${ }^{1,2}$, Sergey Sabadash', Zhenhua Duan² \\ 1 - Sumy National Agrarian University, Sumy, Ukraine \\ 2 - Hezhou University, Hezhou, China
}

\section{Keywords:}

Beetroot

Drying

Microwave

Rehydration

Article history:

Received

17.01.2021

Received in revised

form 28.03.2021

Accepted

16.07.2021

\section{Corresponding}

author:

Zhenhua Duan

E-mail:

dzh65@126.com

DOI:

$10.24263 / 2310-$

1008-2021-9-1-5

\section{Abstract}

Introduction. The purpose of this study is to explore the effects of intermittent microwave drying conditions (microwave pulse ratio, microwave power density and slice thickness) on drying characteristics and physical properties of beetroots.

Materials and methods. Drying characteristics and physical properties of beetroots were investigated using intermittent microwave drying at different microwave pulse ratios $(1,2,3$, and $4)$, microwave power densities $(1.0,1.5,2.0$, and $2.5 \mathrm{~W} / \mathrm{g})$ and slice thicknesses $(2,4,6$, and $8 \mathrm{~mm})$. Moisture analyzer and portable water activity meter were used to determine moisture content and water activity of beetroots, respectively. The weighing method was used to assess the rehydration capacity of dried beetroots. In order to evaluate the color quality of beetroots, a colorimeter was used.

Results and discussion. The moisture ratio continuously decreased with the extension of drying time at all drying treatments. Except for microwave power density of $2.5 \mathrm{~W} / \mathrm{g}$, all the drying conditions presented a short heating (warm-up) period, an approximately constant rate drying period and a falling rate drying period. Meanwhile, the drying time decreased with increasing microwave power density, while increased significantly with the growth of microwave pulse ratio and slice thickness. There was no significant difference in the final moisture content and water activity of dried beetroots under all drying treatments. The rehydration ratio decreased with the increase of slice thickness (from 2 to $8 \mathrm{~mm}$ ), microwave power density (from 1.5 to $2.5 \mathrm{~W} / \mathrm{g}$ ), and microwave pulse ratio (from 2 to 4). Compared to fresh beetroots, all the beetroots after intermittent microwave drying had lower $a$ and $C$ values, and higher $L$ values.

Conclusions. Considering drying characteristics and physical properties of beetroots, and energy consumption, the optimal microwave intermittent drying conditions for fresh beetroots are microwave pulse ratio of 2 , microwave power density of $2.0 \mathrm{~W} / \mathrm{g}$, and slice thickness of $2 \mathrm{~mm}$. 


\section{Introduction}

As one of the most important and widely grown vegetables, the global production of beetroot (Beta vulgaris L.) was about 301 million tons in 2017 with a harvested area of 4.89 million hectares [1]. Beetroots contain a variety of nutritional and bioactive ingredients, for instance, betalains, polyphenols, ascorbic acids, flavonoids, carotenoids, vitamins, minerals, nitrates, and saponins [2]. Recent studies have shown a variety of health benefits for beetroots, such as antioxidative, anti-inflammation, antidiabetic, anticancer, anti-obesity effects, blood pressure and lipid lowering [3]. Due to its good taste and high nutritional value, beetroots are widely consumed and used for manufacturing food coloring agents [4]. Beetroot is prone to spoilage due to its high moisture content, making it perishable.

Drying is one of most widely used methods for preservation of fresh vegetables and fruits, which can prevent microbial spoilage and deterioration reactions and allow their use during off-season [5]. Microwave drying is an efficient drying method, can enhancement of heat and mass transfer, development of internal moisture gradients which increase drying rate as well as improvement of product quality [6]. However, the continuous microwave heating may easily cause rapid heat transfer, the risk of hot spots, product overheating, and undesirable changes in quality [7]. Intermittent microwave drying or microwave intermittent drying was proposed on the basis of conventional microwave drying by considering the existing problems. In intermittent microwave drying, temperature and moisture are redistributed within the product during the microwave off time [8]. Realizing the benefits of intermittent microwave drying, several researchers have explored experimentally drying kinetics and quality of different vegetables and fruits dried by intermittent microwave drying. Zhao et al. [9] investigated the physical changing trend and mechanism of litchi under microwave intermittent drying. Aghilinategh et al. [10] studied the effects of intermittent microwave convective drying parameters on apple color properties. Dai et al. [11] explored the drying characteristics and modeling of apple slices during microwave intermittent drying. There are few studies on intermittent microwave drying of beetroots.

This study proposes a way of improving the drying characteristics and quality indicators of beetroots through the application of intermittent microwave drying.

The objective of the study is to explore the effects of microwave pulse ratio, microwave power density and slice thickness on drying characteristics and physical properties (moisture content, water activity, color, and rehydration ratio) of beetroots.

\section{Materials and methods}

\section{Materials}

Fresh beetroots (Beta vulgaris L.) were purchased from a local market in the city of Xuzhou in Jiangsu Province, China. Before drying, beetroots were stored in a refrigerator at $4{ }^{\circ} \mathrm{C}$. At the beginning of each experiment, whole fresh beetroots were washed by running water. The washed beetroots were peeled and then cut transversely with a stainless steel slicer, chopped into 80-mm diameter slices with different thicknesses.

\section{Design of intermittent microwave drying conditions}

To investigate the drying characteristics and physical properties of beetroots, a fourlevel factorial experimental design with three factors, namely microwave pulse ratio, 


\section{- Food Technology —}

microwave power density and slice thickness was constructed. The levels of microwave pulse ratio were $1,2,3$, and 4 , respectively, microwave power density were 1.0, 1.5, 2.0, and 2.5 $\mathrm{W} / \mathrm{g}$, respectively, and those of slice thickness were $2,4,6$, and $8 \mathrm{~mm}$, respectively. The microwave pulse ratio (PR) was calculated by the following equation [12]:

$$
P R=\frac{t_{o n}+t_{o f f}}{t_{o n}}
$$

Where $t_{\text {on }}$ is the microwave on-time, and $t_{\text {off }}$ shows the microwave off-time. The microwave on-off time employed in this intermittent microwave drying was as following: 3 min on -0 min off $(P R=1), 3$ min on -3 min off $(P R=2), 3$ min on -6 min off $(P R=3)$, and 3 min on -9 min off $(P R=4)$.

Weighed slices of fresh beetroots ( $260 \pm 2 \mathrm{~g}$ total mass), were placed symmetrically on a $30-\mathrm{cm}$ diameter circular fiberglass plate (turntable), which was mounted inside the drying chamber and rotated at $4 \mathrm{rpm}$ to ensure uniform microwave irradiation. A microwave drying system (SAM-255, CEM Corporation, USA) with a maximum output of $650 \mathrm{~W}$ at $2450 \mathrm{MHz}$ was used in the experiments. During the drying process, the change in the beetroots' weight was recorded at intervals of $3 \mathrm{~min}$ by an electronic balance (CP512, Ohaus Instrument Co. Ltd., China). Drying was carried out until the beetroots presented $0.04 \mathrm{~g} / \mathrm{g}$ on a dry basis. All drying experiments were repeated five times.

\section{Determination of moisture content and water activity}

The moisture content (wet basis) of beetroots was determined by a moisture analyzer (HX204, Mettler Toledo Co. Ltd., Switzerland) at $105^{\circ} \mathrm{C}$. Moisture content (MC) on the dry basis was calculated using the following equation [13]:

$$
M C=\frac{M_{\mathrm{w}}}{M_{\mathrm{s}}}
$$

where $M_{\mathrm{w}}$ is the water mass $(\mathrm{g})$ and $M_{s}$ is the mass of sample's dry solids $(\mathrm{g})$. Average initial moisture content of beetroot was $12.02 \mathrm{~g}$ water/g dry solids $(\mathrm{g} / \mathrm{g})$.

The water activity of beetroots was determined by a portable water activity meter (Aqualab 4TE Duo, Rotronic Co. Ltd., USA) at $25^{\circ} \mathrm{C}$.

\section{Moisture ratio}

Moisture ratio (MR) was calculated by using the following expression:

$$
M R=\frac{M_{t}-M_{e}}{M_{0}-M_{e}}
$$

where the $M_{t}, M_{0}$, and $M_{e}$ are moisture content of sample at any time, initial time, and equilibrium, respectively $(\mathrm{g} / \mathrm{g})$. For microwave drying, it can be assumed that $M_{e}=0$ [14].

\section{Drying time}

The time taken to the moisture content of beetroots from the initial level $(12.02 \mathrm{~g} / \mathrm{g})$ to $0.04 \mathrm{~g} / \mathrm{g}$ under various intermittent microwave drying conditions was identified as drying 
time. Therefore, the drying time of beetroots includes microwave on time and microwave off time.

\section{Drying rate}

The drying rate (DR) was calculated according to the following equation [15]:

$$
D R=\frac{M_{t}-M_{t+\Delta t}}{\Delta \mathrm{t}}
$$

where $D R$ is the drying rate, $\mathrm{g} /(\mathrm{g} \cdot \mathrm{min}) ; M_{t+\Delta t}$ and $M_{t}$ are the dry basis moisture content of the sample at $\mathrm{t}+\Delta \mathrm{t}$ and $\mathrm{t}$ respectively, $\mathrm{g} / \mathrm{g} ; \Delta \mathrm{t}$ is the time difference between two consecutive measurements, min.

\section{Determination of rehydration capacity}

The rehydration capacity was performed by dipping $2.0 \mathrm{~g}$ dried beetroots into $200 \mathrm{~mL}$ of distilled water at $80{ }^{\circ} \mathrm{C}$ for $15 \mathrm{~min}$. The rehydrated beetroots were taken out, the surface moisture of rehydrated beetroots were absorbed with absorbent papers, and then weighed. The test was performed thrice. Rehydration ratio of dried beetroots was calculated by the following expression [16]:

$$
R R=\frac{m_{2}}{m_{1}}
$$

where $R R$ is the rehydration ratio; $m_{1}$ is the mass of dried beetroots, $\mathrm{g} ; m_{2}$ is the mass of beetroots after rehydration, $g$.

\section{Determination of color parameters}

Color of beetroots was measured using a colorimeter (CR-400, Konica Minolta Sensing, Inc., Osaka, Japan). The beetroots dried by different intermittent microwave drying conditions and fresh beetroots were grounded and the measured. The samples were placed in a standard light and the Hunter $L$ (lightness), $a$ (redness), and $b$ (yellowness) values were determined. The $L, a, b$ values were used to calculate total color difference $(\Delta E)$, chroma $(C)$ and hue angle $\left(H^{\circ}\right)$ to describe color changes after drying. $C$ changes from 0 (dull) to 60 (vivid) and was calculated by Equation (6) [17].

$$
C=\sqrt{a^{2}+b^{2}}
$$

The color of food samples generally characterizes by calculating hue angle $\left(H^{\circ}\right)$ value as shown in the Equation (7). Values of $H^{\circ}$ range from $0^{\circ}$ (red), $90^{\circ}$ (yellow), $180^{\circ}$ (green) to $270^{\circ}$ (blue) [18].

$$
H^{\circ}=\tan ^{-1}\left(\frac{b}{a}\right)
$$

Total color change $(\Delta E)$ indicates the magnitude of color change after drying and was evaluated by using the following equation [10]. 


$$
\begin{aligned}
& \text { Food Technology - } \\
& \Delta E=\sqrt{\left(L-L_{0}\right)^{2}+\left(a-a_{0}\right)^{2}+\left(b-b_{0}\right)^{2}}
\end{aligned}
$$

where $L, a$, and $b$ are the values of dried beetroots, $L_{0}, a_{0}$, and $b_{0}$ are the values of fresh beetroots. The measurements were done 5 times for each sample.

\section{Statistical analysis}

The experimental results were expressed as mean \pm standard deviation (SD). The responses of the physical analyzes were submitted to analysis of variance (ANOVA), followed by the Duncan's Test $(\mathrm{p}<0.05)$ using SPSS 20.0 for Windows (SPSS Inc., Chicago, IL, USA). Figures were drawn using Origin 2017 (Origin Lab, MA, USA)

\section{Results and discussion}

\section{Physical properties of fresh beetroots}

The fresh beetroots were analyzed physical properties, which are given in Table 1. The beetroot used is high water content vegetable. The moisture content of fresh beetroots was as high as $92.32 \pm 1.37 \%$ on a wet basis, and the water activity up to $0.9852 \pm 0.0025$. Lightness $(L)$, redness (positive $a$ ) and yellowness (positive $b$ ) of fresh beetroots were $36.83 \pm 1.14$, $28.78 \pm 2.22$ and $6.35 \pm 1.06$, respectively. The $H^{\circ}$ value of fresh beetroots was $4.53 \pm 0.48$, indicating a greater tendency to reddish hue.

Physical properties of fresh beetroots (before drying)

Table 1

\begin{tabular}{|c|c|}
\hline Attribute & Content \\
\hline Initial moisture content, $\%$ & $92.32 \pm 1.37$ \\
\hline Water activity & $0.9852 \pm 0.0025$ \\
\hline$L$ & $36.83 \pm 1.14$ \\
\hline$a$ & $28.78 \pm 2.22$ \\
\hline$b$ & $6.35 \pm 1.06$ \\
\hline$C$ & $29.47 \pm 2.39$ \\
\hline$H^{\circ}$ & $4.53 \pm 0.48$ \\
\hline
\end{tabular}

\section{Effect of microwave pulse ratio on drying characteristics and physical properties of beetroots}

Microwave pulse ratio represents a ratio which is calculated by dividing the sum of the microwave on and off time by the microwave on time [12]. In order to determine the influence of microwave pulse ratio on the drying characteristics and physical properties of beetroots, the beetroots were dried at the slice thickness of $4 \mathrm{~mm}$ and microwave power density of 2.0 $\mathrm{W} / \mathrm{g}$, and the microwave pulse ratio ranged $1,2,3$, and 4 .

Figure 1 presents the drying curves of beetroots at different microwave pulse ratios. As can be seen, the moisture ratio (MR) decreased as drying process at all microwave pulse ratios, and the shortest drying time was obtained using the lower microwave pulse ratio (PR $=1)$. 


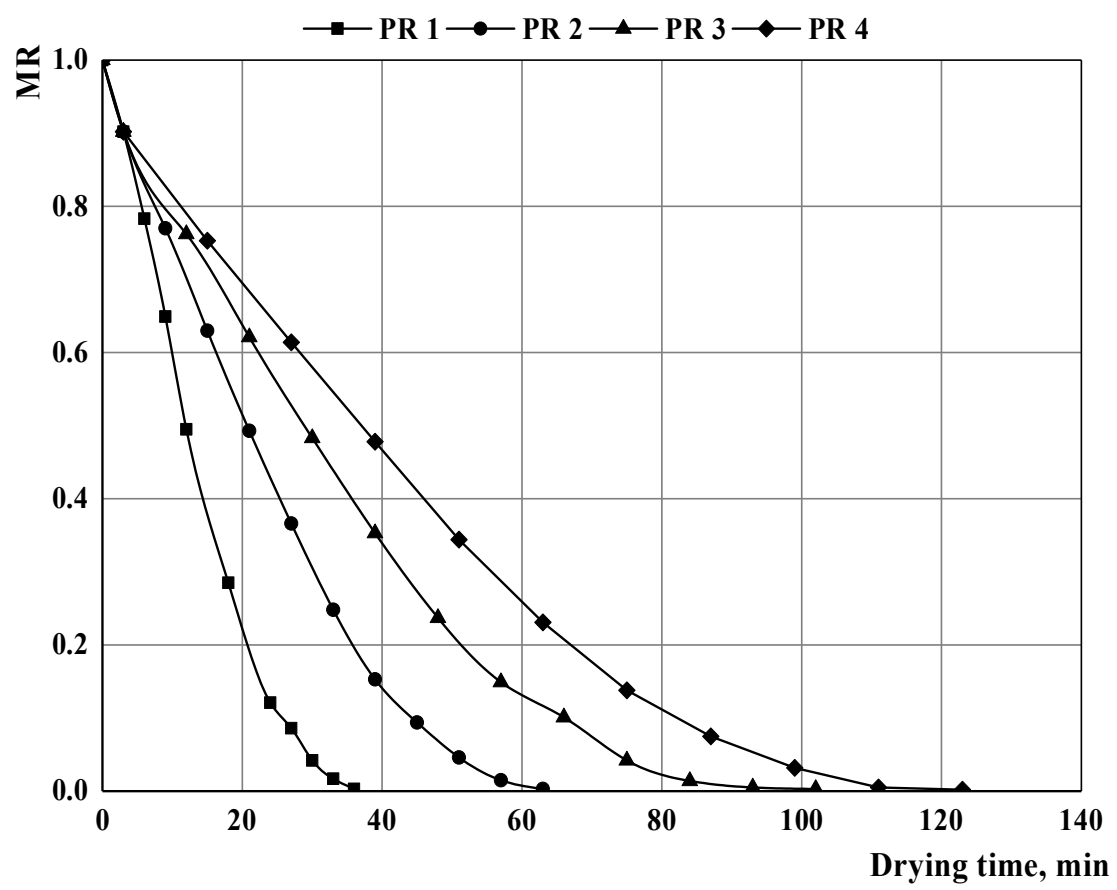

Figure 1. Drying curves of the beetroots at different microwave pulse ratios

The drying rates $(D R)$ of the beetroots at different microwave pulse ratios are shown in Figure 2.

It was reported that microwave drying of high initial moisture materials has three periods, a short heating period, a constant drying rate period and a falling drying rate period [19]. For beetroots dried at microwave pulse ratio of $1(\mathrm{PR}=1)$, the whole drying process took place in a warm-up period (short heating period) and then showed a falling-rate phase, not existence of a constant drying rate period. When the microwave pulse ratios were 2, 3, and 4, three well-defined drying periods were evident, a short heating period, a constant drying rate, and a falling drying rate period. As microwave pulse ratio increased, the length of the constant drying rate period increased. This phenomenon could be due to the longer microwave off time, which provided longer rest time for better moisture and temperature distribution inside the sample until the following microwave on time [20]. Similar findings are founded in various intermittent microwave drying of grated carrots [21] and cranberries [22].

The moisture content, water activity, drying time and rehydration ratio of beetroots at different microwave pulse ratios can be seen in Table 2 . 


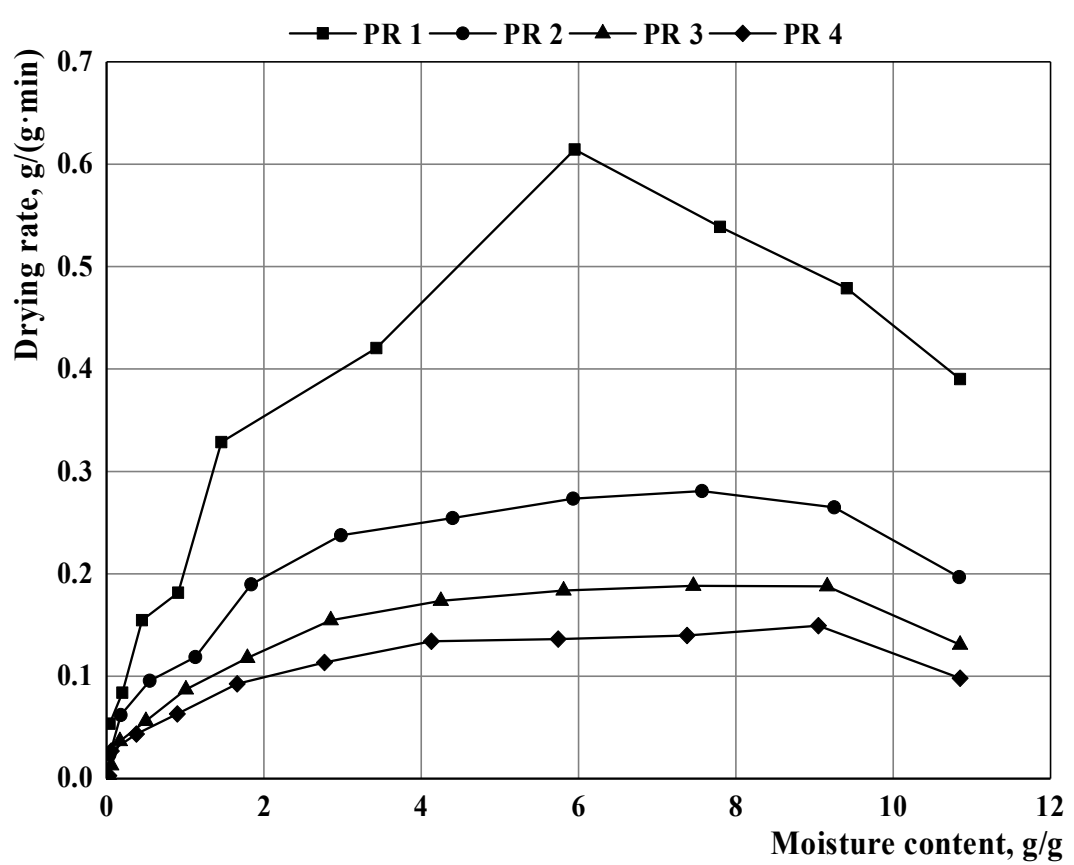

Figure 2. Drying rate variations of beetroot as a function of moisture on a dry basis at different microwave pulse ratios

Table 2

Moisture content, water activity, drying time and rehydration ratio of beetroots at different microwave pulse ratios

\begin{tabular}{|c|c|c|c|c|}
\hline $\begin{array}{c}\text { Microwave } \\
\text { pulse ratio }\end{array}$ & $\begin{array}{c}\text { Moisture } \\
\text { content, \% }\end{array}$ & Water activity & $\begin{array}{c}\text { Drying time, } \\
\text { min }\end{array}$ & $\begin{array}{c}\text { Rehydration } \\
\text { ratio }\end{array}$ \\
\hline 1 & $3.59 \pm 0.62^{\mathrm{a}}$ & $0.2954 \pm 0.0152^{\mathrm{a}}$ & $35.4 \pm 1.2^{\mathrm{d}}$ & $5.27 \pm 0.16^{\mathrm{ab}}$ \\
\hline 2 & $3.69 \pm 0.48^{\mathrm{a}}$ & $0.2988 \pm 0.0121^{\mathrm{a}}$ & $61.8 \pm 2.4^{\mathrm{c}}$ & $5.48 \pm 0.10^{\mathrm{a}}$ \\
\hline 3 & $3.65 \pm 0.66^{\mathrm{a}}$ & $0.2974 \pm 0.0176^{\mathrm{a}}$ & $96.6 \pm 4.4^{\mathrm{b}}$ & $5.05 \pm 0.10^{\mathrm{bc}}$ \\
\hline 4 & $3.59 \pm 0.49^{\mathrm{a}}$ & $0.2946 \pm 0.0106^{\mathrm{a}}$ & $115.8 \pm 5.9^{\mathrm{a}}$ & $4.94 \pm 0.08^{\mathrm{c}}$ \\
\hline
\end{tabular}

*Different letters in the same column represent significant differences according to Duncan's Test ( $p$ $<0.05)$.

Fresh beetroots had a moisture content of $92.32 \pm 1.37 \%$, which were dried to moisture content of less than $4.00 \%$. As shown in Table 2, the final moisture content of beetroots ranged from $3.59 \pm 0.62 \%$ to $3.69 \pm 0.48 \%$ on a wet basis, with no significant difference among all the microwave pulse ratios. In addition to reducing the weight and volume of materials, the reduction of moisture also helps increase the stability of dried products, and increases the service life and facilitates the transportation and storage of the product, thereby reducing waste and cost [23]. The water activity $\left(a_{w}\right)$ of dried beetroots was between $0.2946 \pm 0.0106$ and $0.2988 \pm 0.0121$ (Table 2), and there was no significant difference among all the 
microwave pulse ratios. The reduction of $a_{w}$ can minimize reactions of deterioration and growth of microorganisms, which contribute to the conservation and extension of the product shelf life [24]. The drying time of beetroots at different microwave pulse ratios from initial moisture content of $12.02 \mathrm{~g} / \mathrm{g}$ to reach the desired moisture content of $0.04 \mathrm{~g} / \mathrm{g}$ is shown in Table 2. It can be seen from Table 2 that the drying time increased significantly $(p<0.05)$ with the increase of microwave pulse ratio. The drying time with the microwave pulse ratio of 1 was the shortest $(35.4 \pm 2.6 \mathrm{~min})$, while the drying time with the microwave pulse ratio of 4 was the longest $(115.8 \pm 5.9 \mathrm{~min})$. It was found that the whole drying time increased by about $227.1 \%$ as the microwave pulse ratio changed from 1 to 4 .

Rehydration capacity is a major quality parameter of dried products, which indicates the ability of the product to maintain its original shape and reflects the degree of damage to the cellular during the drying process [25]. The rehydration ratio of beetroots increased with an increase in microwave pulse ratio from 1 to 2 and decreased with a decrease in microwave pulse ratio from 3 to 4 . Dried beetroots at microwave pulse ratio of 2 showed the highest rehydration ratio $(5.48 \pm 0.10)$ as compared to other microwave pulse ratios. At microwave pulse ratio values of 1 to 2 , the beetroots exhibited a high degree of drying and strong ability to absorb water. Increasing microwave pulse ratio prolonged the off time for drying beetroots. Less porous structures were formed when the microwave was turned off, resulted in a reduced rehydration ratio [26]. Similar observation was also reported in microwave vacuum drying of tilapia fillets [27].

The results of color changes in beetroots for all microwave pulse ratios are given in Table 3 .

Color parameters of dried beetroots as affected by microwave pulse ratios

Table 3

\begin{tabular}{|c|c|c|c|c|}
\hline \multirow{2}{*}{ Color } & \multicolumn{4}{|c|}{ Microwave pulse ratio } \\
\cline { 2 - 5 } & 1 & 2 & 3 & 4 \\
\hline$L$ & $48.96 \pm 0.85^{\mathrm{a}}$ & $48.29 \pm 0.98^{\mathrm{ab}}$ & $47.72 \pm 0.89^{\mathrm{ab}}$ & $46.91 \pm 0.78^{\mathrm{b}}$ \\
\hline$a$ & $26.03 \pm 0.38^{\mathrm{a}}$ & $24.97 \pm 0.79^{\mathrm{b}}$ & $22.54 \pm 0.42^{\mathrm{c}}$ & $20.98 \pm 0.15^{\mathrm{d}}$ \\
\hline$b$ & $5.27 \pm 0.23^{\mathrm{b}}$ & $6.68 \pm 0.35^{\mathrm{a}}$ & $5.36 \pm 0.25^{\mathrm{b}}$ & $5.51 \pm 0.05^{\mathrm{b}}$ \\
\hline$C$ & $26.55 \pm 0.42^{\mathrm{a}}$ & $25.85 \pm 0.84^{\mathrm{a}}$ & $23.17 \pm 0.47^{\mathrm{b}}$ & $21.69 \pm 0.17^{\mathrm{c}}$ \\
\hline$H^{\circ}$ & $4.88 \pm 0.14^{\mathrm{a}}$ & $3.58 \pm 0.11^{\mathrm{c}}$ & $4.13 \pm 0.12^{\mathrm{b}}$ & $3.72 \pm 0.05^{\mathrm{c}}$ \\
\hline$\Delta E$ & $12.49 \pm 0.91^{\mathrm{a}}$ & $12.10 \pm 1.12^{\mathrm{a}}$ & $12.60 \pm 0.87^{\mathrm{a}}$ & $12.80 \pm 0.9^{\mathrm{a}}$ \\
\hline
\end{tabular}

*Data in the same row with different letters are significantly different according to Duncan's Test $(p<0.05)$.

Obviously, it can be seen that the $L$ values after drying were significantly higher than that of fresh beetroots. The lowest $L$ value obtained from the beetroots dried by microwave pulse ratio of 4 , which had darker color than other microwave pulse ratios. Compared to fresh beetroots, $a$ (redness) values significantly decreased after drying by different microwave pulse ratios. It can be seen that $a$ (redness) value decreased with the increasing of microwave pulse ratio. The $a$ values of dried beetroots were significantly affected by microwave pulse ratio $(p<0.05)$. The decrease of $a$ value might be due to the degradation of pigments such as betacyanins. The highest $b$ value $(6.68 \pm 0.35)$ was obtained from beetroots dried at microwave pulse ratio of 2 , which was significant higher than that of other microwave pulse ratios $(p<0.05)$. 
The $C$ values of beetroots dried under different microwave pulse ratios were significantly lower than that of fresh beetroots (see Table 1 and Table 3 ). Dried beetroots at microwave pulse ratio of 1 showed the highest $C$ value $(26.55 \pm 0.42)$ as compared to other microwave pulse ratios. The $C$ values of dried beetroots at microwave pulse ratio of 1 and 2 were significantly higher than $(\mathrm{p}<0.05)$ that of beetroots at microwave pulse ratio of 3 and 4. The lowest $H^{\circ}$ value $(3.58 \pm 0.11)$ was obtained from beetroots dried at microwave pulse ratio of 2 , while the highest value $(4.88 \pm 0.14)$ was obtained from beetroots dried at microwave pulse ratio of 1 . It has been explained that the reduction in $H^{\circ}$ value is an expression of more darkening color [28]. As can be seen from Table 3, microwave pulse ratio has no significant effect on total color change $(\Delta E)(\mathrm{p}>0.05)$.

As a result, the beetroots dried at microwave pulse ratio of 1 showed a greater tendency towards bright, red, greater color saturation and a more yellowish hue compared to the beetroots dried at other microwave pulse ratios.

\section{Effect of microwave power density on drying characteristics and physical properties of beetroots}

The effect of microwave power density on the drying characteristics and physical properties of beetroots was investigated at the microwave pulse ratio of 2 and slice thickness of $4 \mathrm{~mm}$. Four different levels of the microwave power, namely, 260, 390, 520 and $650 \mathrm{~W}$, were investigated. Based on the initial mass of $260 \mathrm{~g}$, of the fresh beetroot slices, these values correspond to microwave power density of $1.0,1.5,2.0$, and $2.5 \mathrm{~W} / \mathrm{g}$, respectively.

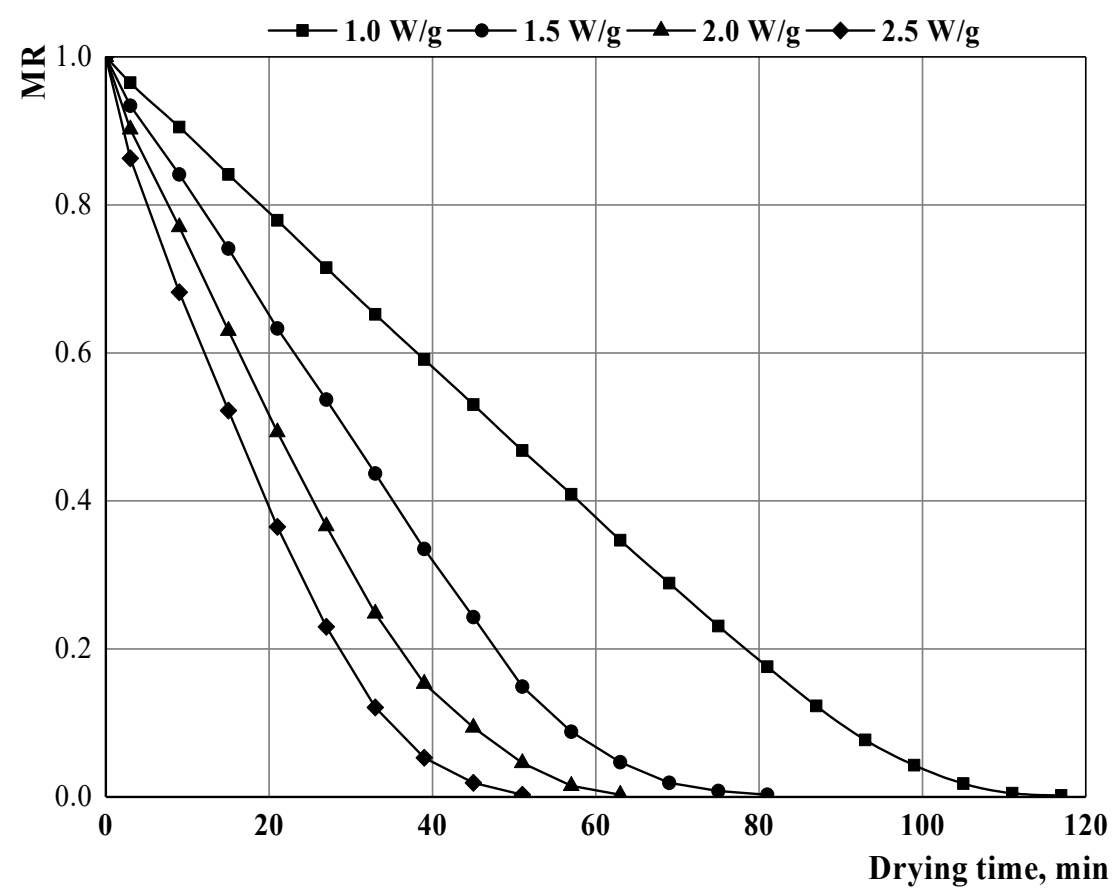

Figure 3. Drying curves of the beetroots at different microwave power densities 
The drying curves of beetroots at different microwave power densities are shown in Figure 3. It can be seen that the moisture ratio gradually decreased with the drying process under all the microwave power densities. It is obvious that the higher the power, the less time necessary to dry the beetroots. Higher microwave power density provides more energy for sublimation, thus accelerating the drying process. It reveals that drying carried out at higher microwave power density give shorter drying duration. Similar results have been reported in microwave drying of apple slices [11] and bitter melon [29].

Figure 4 shows the drying rate curves of beetroots at different microwave power densities.

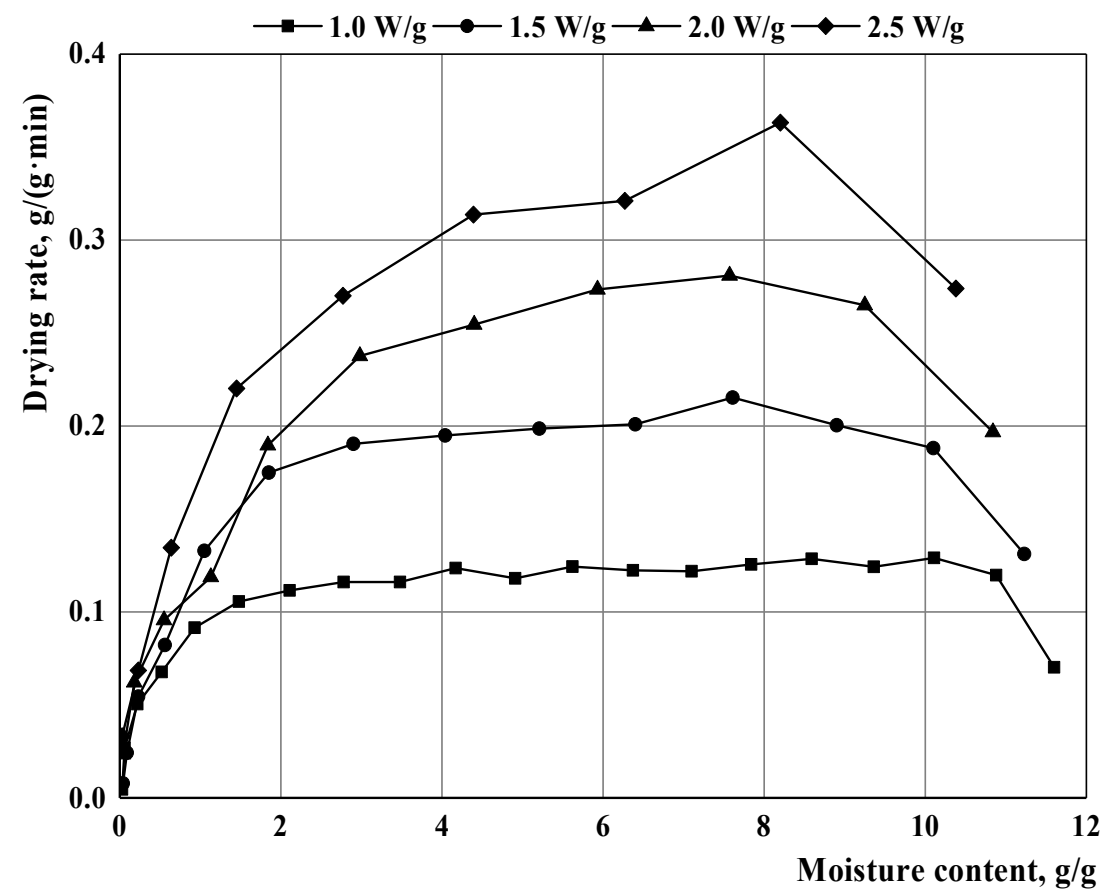

Figure 4. Drying rate variations of beetroot as a function of moisture on a dry basis at different microwave power densities

The drying rate increased with the increase of microwave power density. The reason is that the weaker microwave radiation cannot completely penetrate the material, so the material dehydration starts from the adjacent part of epidermis, and then the dehydrated part forms a relatively tight porous network structure, which hindered the migration and removal of moisture. While the stronger microwave radiation can penetrate the material more effectively so that the material can quickly remove moisture from the inside to the outside [30].

Results showed that intermittent microwave drying at $2.5 \mathrm{~W} / \mathrm{g}$ occurred mainly in the falling rate period, whereas drying at lower powers resulted in relatively longer constant rate periods. It is clearly seen that the drying rate was an increasing trend at the early stage of the drying process (Figure 4). In the initial stage of drying, the inside and outside of the material were heated at the same time, the temperature rose rapidly, and the moisture inside the 
material continuously migrated to the outer surface; meanwhile the outer surface was easier to dissipate due to evaporation and diffusion, causing a temperature gradient difference between the inside and the outside of the material, and the direction of the temperature gradient was the same as the direction of water migration, so the drying rate increased [31]. At 1.0 and $1.5 \mathrm{~W} / \mathrm{g}$, a relatively longer constant drying rate period was observed. In addition, the drying rate was in a decreasing trend (falling rate period) at the final stage of the drying process. After a short heating process during the early stage of drying, the drying rate at 2.5 $\mathrm{W} / \mathrm{g}$ increased to a maximum and then decreased without a distinct constant drying rate period. On the contrary, a relatively long constant rate period was visible at lower specific powers $(1.0$ and $1.5 \mathrm{~W} / \mathrm{g})$. In the middle of drying period, microwave heating is completely used for the vaporization of moisture, and the drying rate is relatively stable. At this time, the rate of water loss on the surface of the beetroots is equal to the rate of outward migration of internal moisture, so there is a constant rate period. In the later stage of drying, the free water in the beetroot was basically removed. At this time, the combined water is mainly contained in the beetroots, and the combined water is more difficult to remove, and the absorbed microwave energy is reduced, so the drying rate gradually decreases and enters the reducedspeed drying stage.

Table 4 shows the moisture content, water activity, drying time and rehydration ratio of beetroots dried at different microwave power densities.

Table 4

Moisture content, water activity, drying time and rehydration ratio of beetroots at different microwave power densities

\begin{tabular}{|c|c|c|c|c|}
\hline $\begin{array}{c}\text { Microwave } \\
\text { power density, } \\
\text { W/g }\end{array}$ & $\begin{array}{c}\text { Moisture } \\
\text { content, \% }\end{array}$ & Water activity & $\begin{array}{c}\text { Drying } \\
\text { time, min }\end{array}$ & $\begin{array}{c}\text { Rehydration } \\
\text { ratio }\end{array}$ \\
\hline 1.0 & $3.60 \pm 0.42^{\mathrm{a}}$ & $0.2947 \pm 0.0090^{\mathrm{a}}$ & $117.0 \pm 3.8^{\mathrm{a}}$ & $5.57 \pm 0.16^{\mathrm{ab}}$ \\
\hline 1.5 & $3.68 \pm 0.44^{\mathrm{a}}$ & $0.2962 \pm 0.0115^{\mathrm{a}}$ & $77.4 \pm 2.9^{\mathrm{b}}$ & $5.82 \pm 0.09^{\mathrm{a}}$ \\
\hline 2.0 & $3.69 \pm 0.48^{\mathrm{a}}$ & $0.2988 \pm 0.0121^{\mathrm{a}}$ & $61.8 \pm 2.4^{\mathrm{c}}$ & $5.48 \pm 0.10^{\mathrm{b}}$ \\
\hline 2.5 & $3.61 \pm 0.55^{\mathrm{a}}$ & $0.2951 \pm 0.0148^{\mathrm{a}}$ & $53.4 \pm 2.9^{\mathrm{d}}$ & $5.11 \pm 0.09^{\mathrm{c}}$ \\
\hline
\end{tabular}

*Different letters in the same column represent significant differences according to Duncan's Test (p $<0.05)$.

The final moisture content of dried beetroots ranged from $3.60 \pm 0.42 \%$ to $3.69 \pm 0.48 \%$ on wet basis, meanwhile, the final water activity ranged from $0.2947 \pm 0.0090$ to $0.2988 \pm 0.0121$. There were no significant difference in the final moisture content and water activity of dried beetroots under different microwave power densities $(p>0.05)$. It can be seen from Table 4 that the drying time decreased significantly with the increase of microwave power densities $(p<0.05)$. The time to dry the beetroots reduced around $47.2 \%$ when microwave power density increased double (from 1.0 to $2.0 \mathrm{~W} / \mathrm{g}$ ), and when the microwave power density was $2.5 \mathrm{~W} / \mathrm{g}$, the drying time was only $45.6 \%$ of that the microwave power density of $1.0 \mathrm{~W} / \mathrm{g}$. The lowest drying time $(53.4 \pm 2.9)$ of beetroots was found at microwave power density of $2.5 \mathrm{~W} / \mathrm{g}$.

It was observed that rehydration ratio decreased as microwave power density increased from 1.5 to $2.5 \mathrm{~W} / \mathrm{g}$. The lowest rehydration ratio $(5.11 \pm 0.09)$ occurred when the microwave 
power was $2.5 \mathrm{~W} / \mathrm{g}$. As we known, the lower rehydration ratio, the more severe damage to the cell structure of the sample.

The color changes of dried beetroots at different microwave power densities are shown in Table 5.

Table 5

Color parameters of dried beetroots as affected by microwave power densities

\begin{tabular}{|c|c|c|c|c|}
\hline \multirow{2}{*}{ Color } & \multicolumn{4}{|c|}{ Microwave power density, W/g } \\
\cline { 2 - 5 } & 1.0 & 1.5 & 2.0 & 2.5 \\
\hline$L$ & $48.60 \pm 1.20^{\mathrm{ab}}$ & $49.99 \pm 1.24^{\mathrm{a}}$ & $48.29 \pm 0.98^{\mathrm{bc}}$ & $46.75 \pm 0.85^{\mathrm{c}}$ \\
\hline$a$ & $23.67 \pm 0.50^{\mathrm{b}}$ & $23.30 \pm 0.67^{\mathrm{b}}$ & $24.97 \pm 0.79^{\mathrm{a}}$ & $23.72 \pm 1.13^{\mathrm{b}}$ \\
\hline$b$ & $6.76 \pm 0.33^{\mathrm{a}}$ & $6.39 \pm 0.41^{\mathrm{a}}$ & $6.68 \pm 0.35^{\mathrm{a}}$ & $5.52 \pm 0.66^{\mathrm{b}}$ \\
\hline$C$ & $24.61 \pm 0.57^{\mathrm{ab}}$ & $24.16 \pm 0.75^{\mathrm{b}}$ & $25.85 \pm 0.84^{\mathrm{a}}$ & $24.35 \pm 1.25^{\mathrm{b}}$ \\
\hline$H^{\circ}$ & $3.41 \pm 0.11^{\mathrm{b}}$ & $3.56 \pm 0.13^{\mathrm{b}}$ & $3.58 \pm 0.11^{\mathrm{b}}$ & $4.26 \pm 0.31^{\mathrm{a}}$ \\
\hline$\Delta E$ & $12.85 \pm 1.25^{\mathrm{ab}}$ & $14.26 \pm 1.39^{\mathrm{a}}$ & $12.10 \pm 1.12^{\mathrm{b}}$ & $11.22 \pm 1.17^{\mathrm{b}}$ \\
\hline
\end{tabular}

*Data in the same row with different letters are significantly different according to Duncan's Test $(p<0.05)$.

Compared to fresh beetroots (Table 1), the $L$ values of dried beetroots increased significantly. The lowest $L$ value $(46.75 \pm 0.85)$ of dried beetroots was obtained at microwave power density of $2.5 \mathrm{~W} / \mathrm{g}$, while the highest value $(49.99 \pm 1.24)$ was obtained at microwave power density of $1.5 \mathrm{~W} / \mathrm{g}$. It can be seen from Table 1 and Table 5 , the $a$ values of beetroots dried at all microwave power densities were lower than that of fresh beetroots. The highest $a$ value $(24.97 \pm 0.79)$ was obtained from beetroots dried at microwave power density of 2.0 $\mathrm{W} / \mathrm{g}$, which was significantly different from other microwave power densities $(p<0.05)$. The lowest $b$ value $(5.52 \pm 0.66)$ was obtained from the beetroots dried by microwave power density of $2.5 \mathrm{~W} / \mathrm{g}$, which was significantly different from other microwave power densities $(p<0.05)$.

It also can be seen from Table 1 and Table 5, the $C$ values of beetroots dried at different power densities were obviously lower than that of fresh beetroots. The highest $C$ value $(25.85 \pm 0.84)$ in the dried beetroots produced using the microwave power density of $2.0 \mathrm{~W} / \mathrm{g}$. It was observed that microwave power density of $1.0,1.5$ and $2.5 \mathrm{~W} / \mathrm{g}$ had no significant effect on $C$ values $(p>0.05)$. It can be seen from Table 5 that the highest $H^{\circ}$ value $(4.26 \pm 0.31)$ was obtained from the beetroots dried at microwave power density of $2.5 \mathrm{~W} / \mathrm{g}$. When the microwave power densities were $1.0,1.5$, and $2.0 \mathrm{~W} / \mathrm{g}$, the effect on the $H^{\circ}$ value was not significant $(p>0.05)$. The highest $\Delta E$ value $(14.26 \pm 1.39)$ was obtained from beetroots dried at microwave power density of $1.5 \mathrm{~W} / \mathrm{g}$, while the lowest value $(11.22 \pm 1.17)$ was obtained from beetroots dried at microwave power density of $2.5 \mathrm{~W} / \mathrm{g}$.

As a result, the beetroots dried at microwave power density of $2.0 \mathrm{~W} / \mathrm{g}$ showed a greater tendency towards red and greater color saturation compared to the beetroots dried at other microwave power densities. 


\section{Effect of slice thickness on drying characteristics and physical properties of beetroots}

To explore the effect of slice thickness on drying characteristics and physical properties of beetroots, the experiments were carried at microwave pulse ratio of 2 , and microwave power density of $2.0 \mathrm{~W} / \mathrm{g}$.

The drying curves of the beetroots at different slice thicknesses are presented in Figure 5. The MR decreased as drying process at all slice thicknesses. As the slice thickness increased, the drying time required for the beetroots to reach final moisture content increased, and the shortest drying time was obtained at the thinnest slice thickness $(2 \mathrm{~mm})$. It reveals that drying carried out at thinner slice thickness gave shorter drying duration.

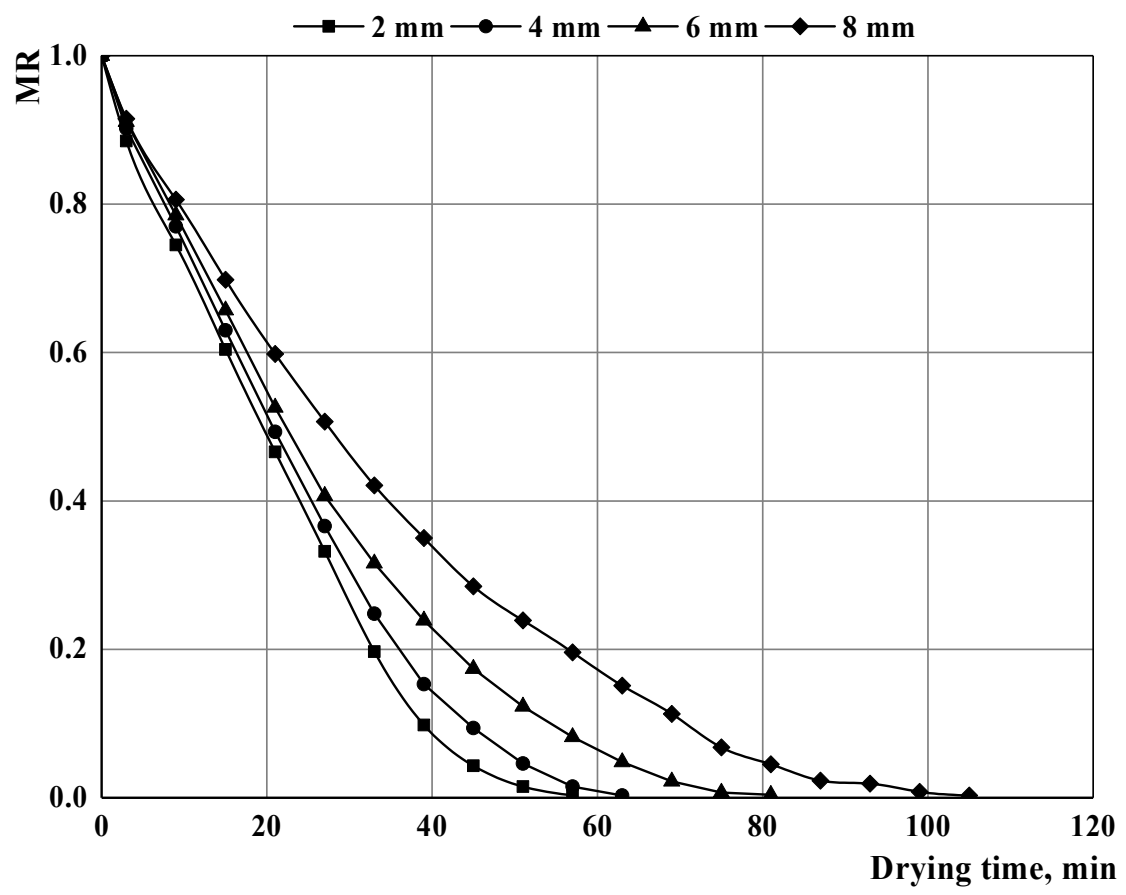

Figure 5. Drying curves of the beetroots at different slice thicknesses

The drying rates (DR) of the beetroots at different slice thicknesses are shown in Figure 6. The DR of beetroots reduced with the increase of slice thickness. This may be attributed to the reason that thicker samples would lead to a longer migration path for the water molecules transferred from inner to external [11]. It is easy to see from Figure 6 that the DR of beetroots was higher at the beginning of drying, when the moisture content of the beetroots was higher. An increase in DR was observed in the initial phase for all slice thicknesses. As can be seen in Figure 6, the constant drying rate time was very short. The DR was gradually reduced until the end of drying, which is due to the reduction of the moisture available for removal and due to the stiffening of the product [24]. It was observed that thinner slice thicknesses resulted in higher DR. The same fact was observed by Dai et al. [11] on microwave intermittent drying of apple slices. 


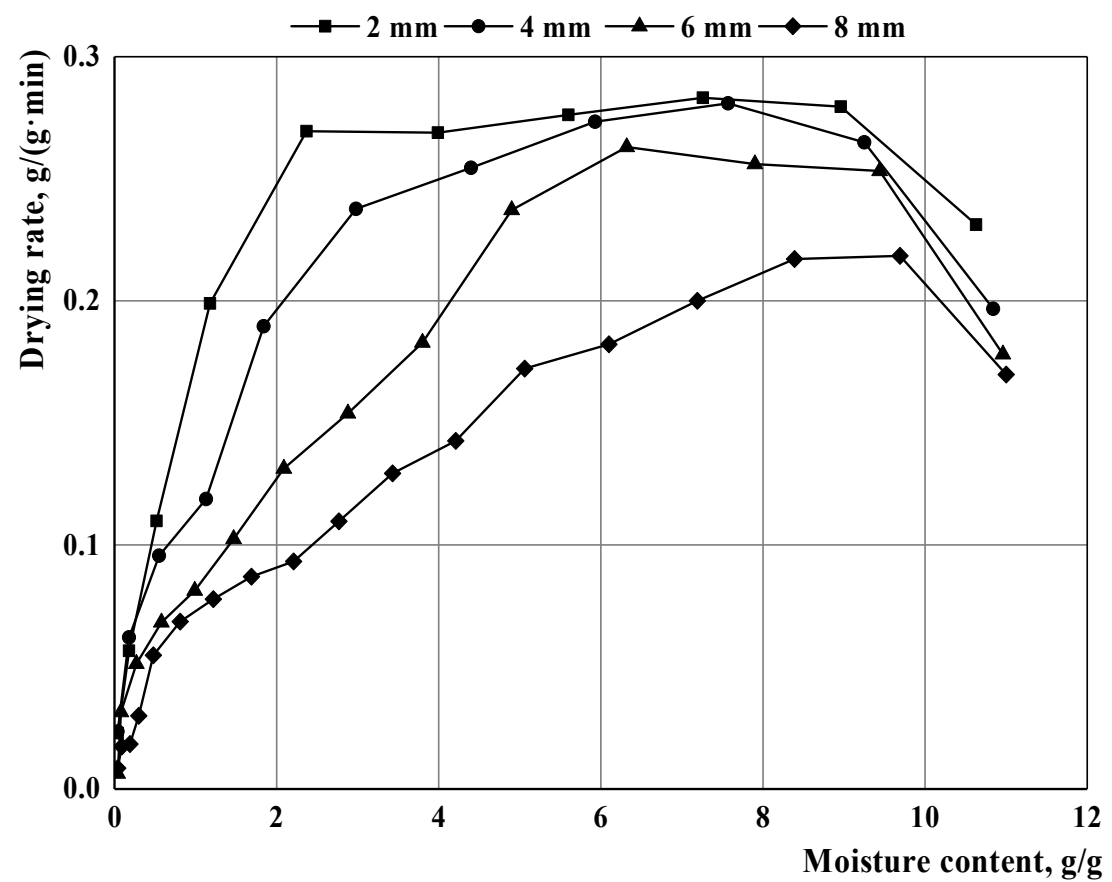

Figure 6. Drying rate variations of beetroot as a function of moisture on a dry basis at different slice thicknesses

Moisture content, water activity, drying time and rehydration ratio of beetroots at different slice thicknesses are presented in Table 6.

Table 6

Moisture content, water activity, drying time and rehydration ratio of beetroots at different slice thicknesses

\begin{tabular}{|c|c|c|c|c|}
\hline $\begin{array}{c}\text { Slice } \\
\text { thickness, mm }\end{array}$ & $\begin{array}{c}\text { Moisture } \\
\text { content, \% }\end{array}$ & Water activity & $\begin{array}{c}\text { Drying time, } \\
\text { min }\end{array}$ & $\begin{array}{c}\text { Rehydration } \\
\text { ratio }\end{array}$ \\
\hline 2 & $3.67 \pm 0.66^{\mathrm{a}}$ & $0.2977 \pm 0.0187^{\mathrm{a}}$ & $54.6 \pm 2.9^{\mathrm{d}}$ & $6.11 \pm 0.14^{\mathrm{a}}$ \\
\hline 4 & $3.69 \pm 0.48^{\mathrm{a}}$ & $0.2988 \pm 0.0121^{\mathrm{a}}$ & $61.8 \pm 2.4^{\mathrm{c}}$ & $5.48 \pm 0.10^{\mathrm{b}}$ \\
\hline 6 & $3.62 \pm 0.60^{\mathrm{a}}$ & $0.2957 \pm 0.0145^{\mathrm{a}}$ & $78.6 \pm 2.9^{\mathrm{b}}$ & $4.45 \pm 0.13^{\mathrm{c}}$ \\
\hline 8 & $3.61 \pm 0.46^{\mathrm{a}}$ & $0.2961 \pm 0.0108^{\mathrm{a}}$ & $102.6 \pm 4.8^{\mathrm{a}}$ & $3.85 \pm 0.05^{\mathrm{d}}$ \\
\hline
\end{tabular}

${ }^{*}$ Different letters in the same column represent significant differences according to Duncan's Test $(p$ $<0.05)$.

The final moisture content of dried beetroots ranged from $3.61 \pm 0.46 \%$ to $3.69 \pm 0.48 \%$ on a wet basis, with no significant difference among all the slice thicknesses. There was no significant difference in the water activity of dried beetroots obtained at all slice thicknesses, and the final water activity was between $0.2957 \pm 0.0145$ and $0.2988 \pm 0.0121$. It can be seen 
from Table 6 that slice thickness had a significant effect on drying time of beetroots. The drying time of beetroots increased significantly with the increase of slice thickness $(p<0.05)$. The time to dry the beetroots increased around $87.9 \%$ when slice thickness increased quadruple (from 2 to $8 \mathrm{~mm}$ ). In other words, the drying time of beetroot slices with a thickness of $2 \mathrm{~mm}$ was only $53.2 \%$ of that of beetroot slices with a thickness of $8 \mathrm{~mm}$.

It was observed that the rehydration ratio was significantly influenced $(p<0.05)$ by the slice thickness (Table 6), in which the higher slice thickness resulted in lower rehydration ratio. The highest rehydration ratio $(6.11 \pm 0.14)$ was obtained from beetroots with a slice thickness of $2 \mathrm{~mm}$, while the lowest value $(3.85 \pm 0.05)$ was obtained from beetroots with a slice thickness of $8 \mathrm{~mm}$. The rehydration ratio of beetroot slices with a thickness of $8 \mathrm{~mm}$ was only $63 \%$ that of beetroot slices with a thickness of $2 \mathrm{~mm}$.

The color parameters of dried beetroots at different slice thicknesses are shown in Table 7.

Color parameters of dried beetroots as affected by slice thicknesses

Table 7

\begin{tabular}{|c|c|c|c|c|}
\hline \multirow{2}{*}{ Color } & \multicolumn{4}{|c|}{ Slice thickness, mm } \\
\cline { 2 - 5 } & 2 & 4 & 6 & 8 \\
\hline$L$ & $50.46 \pm 0.61^{\mathrm{a}}$ & $48.29 \pm 0.98^{\mathrm{b}}$ & $49.72 \pm 0.53^{\mathrm{ab}}$ & $48.84 \pm 1.49^{\mathrm{b}}$ \\
\hline$a$ & $26.47 \pm 0.23^{\mathrm{a}}$ & $24.97 \pm 0.79^{\mathrm{b}}$ & $22.32 \pm 0.56^{\mathrm{c}}$ & $21.99 \pm 0.61^{\mathrm{c}}$ \\
\hline$b$ & $6.44 \pm 0.13^{\mathrm{b}}$ & $6.68 \pm 0.35^{\mathrm{b}}$ & $8.72 \pm 0.41^{\mathrm{a}}$ & $8.35 \pm 0.43^{\mathrm{a}}$ \\
\hline$C$ & $27.24 \pm 0.26^{\mathrm{a}}$ & $25.85 \pm 0.84^{\mathrm{b}}$ & $23.96 \pm 0.67^{\mathrm{c}}$ & $23.52 \pm 0.71^{\mathrm{c}}$ \\
\hline$H^{\circ}$ & $4.03 \pm 0.06^{\mathrm{a}}$ & $3.58 \pm 0.11^{\mathrm{b}}$ & $2.43 \pm 0.07^{\mathrm{c}}$ & $2.51 \pm 0.09^{\mathrm{c}}$ \\
\hline$\Delta E$ & $13.83 \pm 0.62^{\mathrm{a}}$ & $12.10 \pm 1.12^{\mathrm{b}}$ & $14.63 \pm 0.55^{\mathrm{a}}$ & $13.98 \pm 1.34^{\mathrm{a}}$ \\
\hline
\end{tabular}

*Data in the same row with different letters are significantly different according to Duncan's Test $(p<0.05)$.

The $L$ values for all slice thicknesses were in the range of $48.29 \pm 0.98$ to $50.46 \pm 0.61$, which were higher than that of fresh beetroots (see Table 1). The maximum $L$ value appeared in beetroots with a thickness of $2 \mathrm{~mm}$. It was observed that increasing slice thicknesses decreased $a$ value. The decrease in values of $a$ was caused by the degradation of pigments such as betacyanins.

The lowest $a$ value $(21.99 \pm 0.61)$ of dried beetroots was obtained at $8 \mathrm{~mm}$, compared with dried beetroots of other slice thicknesses. The $b$ values of dried beetroots with different thicknesses were higher than that of fresh beetroots. The largest $b$ value $(8.72 \pm 0.41)$ occurred when thickness of the beetroots was $6 \mathrm{~mm}$.

It has been reported that $C$ value is a good illustration of the amount of color, can distinguishing vivid and dull color [32]. Compared to fresh samples, the $C$ values of dried beetroots at different slice thicknesses were significantly reduced. It can be seen from Table 7 that the increase in slice thickness led to a decrease in $C$ value. The lower $C$ value of dried beetroots at $8 \mathrm{~mm}$ indicated less saturation and a duller appearance compared with dried beetroots in other slice thicknesses. The $H^{\circ}$ values of dried beetroots showed a significant decrease as the slice thickness increased from 2 to $6 \mathrm{~mm}$, and lower than that of fresh beetroots. The $H^{\circ}$ value of dried beetroots with a thickness of $6 \mathrm{~mm}$ was the lowest $(2.43 \pm 0.07)$. The highest $\Delta E$ value $(14.63 \pm 0.55)$ was obtained from beetroots dried at slice thickness of $6 \mathrm{~mm}$, while the lowest value $(12.10 \pm 1.12)$ was obtained from beetroots dried at slice thickness of $4 \mathrm{~mm}$. 
As a result, the dried beetroots with thickness of $2 \mathrm{~mm}$ showed a greater tendency towards bright, red, greater color saturation and a more yellowish hue compared to the dried beetroots of other slice thicknesses.

\title{
Conclusion
}

- The effects of microwave pulse ratio, microwave power density and slice thickness were significant on the drying rates, drying time, rehydration capacities and color quality;

- $\quad$ The moisture ratio decreased as drying process at all drying treatments;

- The short heating (warm-up) periods, approximately constant rate drying periods and falling rate drying periods were found in all the drying rate curves, except for the microwave power density of $2.5 \mathrm{~W} / \mathrm{g}$;

- $\quad$ The drying time decreased with increasing microwave power density, while increased significantly with the growth of microwave pulse ratio and slice thickness;

- There was no significant difference in the final moisture content and water activity of dried beetroots under all the microwave drying conditions;

- $\quad$ The rehydration ratio decreased with the increase of slice thickness (from 2 to $8 \mathrm{~mm}$ ), microwave power density (from 1.5 to $2.5 \mathrm{~W} / \mathrm{g}$ ), and microwave pulse ratio (from 2 to 4);

- All the beetroots after intermittent microwave drying had lower values of $a$ and $C$, and higher values of $L$ than fresh beetroots;

- Considering drying characteristics and physical properties of beetroots, and energy consumption, fresh beetroot slices with $2 \mathrm{~mm}$ dried at microwave power density of $2.0 \mathrm{~W} / \mathrm{g}$ and microwave pulse ratio of 2 were proposed as the most economic and favorable drying conditions.

\begin{abstract}
Acknowledgements. This research work was financially supported by Guangxi First-class Discipline Food Science and Engineering Cultivation Project (GXYLXKP1816) and Hezhou Innovationdriven Development Project (hekechuang PT1907006). The authors are grateful to Hezhou Key Laboratory of Microwave Applications, and Research Institute of Food Science and Engineering Technology, Hezhou University, Hezhou, China for providing laboratory facilities and technical support during this research work.
\end{abstract}

\section{References}

1. Oliveira S., Nascimento H., Sampaio K., Souza E. (2020), A review on bioactive compounds of beet (Beta vulgaris L. subsp. vulgaris) with special emphasis on their beneficial effects on gut microbiota and gastrointestinal health, Critical Reviews in Food Science and Nutrition, 61(2), pp. 2022-2033.

2. Fu Y., Shi J., Xie S.Y., Zhang T.Y., Soladoye O.S., Aluko R.E. (2020), Red beetroot betalains: perspectives on extraction, processing, and potential health benefits, Journal of Agricultural and Food Chemistry, 68(42), pp.11595-11611. 
3. Hadipour E., Taleghani A., Tayarani-Najaran N., Tayarani-Najaran Z. (2020), Biological effects of red beetroot and betalains: A review, Phytotherapy Research, 34, pp. 1847-1867.

4. Chhikara N., Kushwaha K., Jaglan S., Sharma P., Panghal A. (2019), Nutrition, physicochemical, and functional quality of beetroot (Beta vulgaris L.) incorporated Asian noodles. Cereal Chemistry, 96, pp. 154-161.

5. Nistor O.V., Ceclu L.S., Andronoiu D.G., Rudi L., Botez E. (2017), Influence of different drying methods on the physicochemical properties of red beetroot (Beta vulgaris L. var. Cylindra), Food Chemistry, 236, pp. 59-67.

6. Chua K.J., Chou S.K. (2005), A comparative study between intermittent microwave and infrared drying of bioproducts, International Journal of Food Science and Technology, 40, pp. 23-39.

7. Szadzińska J., Mierzwa D., Pawłowski A., Musielak G., Pashminehazar R., Kharaghani A. (2020), Ultrasound- and microwave-assisted intermittent drying of red beetroot, Drying Technology, 38(1-2), pp. 93-107.

8. Pham N.D., Khan M.I.H., Karim M.A. (2020), A mathematical model for predicting the transport process and quality changes during intermittent microwave convective drying, Food Chemistry, 325(6), DOI:10.1016/j.foodchem.2020.126932

9. Zhao Y.K., Li C.Y., Chen Y., Chen Z. (2015), Physical changes and mechanism of whole litchi in the process of intermittent microwave drying. Science and Technology of Food Industry, 8, pp. 81-84.

10. Aghilinategh N., Rafiee S., Hosseinpour S., Omid M., Mohtasebi S.S. (2015), Optimization of intermittent microwave-convective drying using response surface methodology, Food Science \& Nutrition, 3(4), pp. 331-341.

11. Dai J-W., Xiao H-W., Zhang L-H., Chu M-Y., Qin W., Wu Z-J., Han D-D., Li Y-L., Liu YW., Yin P-F. (2019), Drying characteristics and modeling of apple slices during microwave intermittent drying, Journal of Food Process Engineering, 42(5), DOI:10.1111/jfpe.13212

12. Gunasekaran S. (1999), Pulsed microwave-vacuum drying of food materials, Drying Technology, 17(3), pp. 395-412.

13. Dehghannya J., Naghavi E.-A., Ghanbarzadeh B. (2016), Frying of potato strips pretreated by ultrasound-assisted air-drying, Journal of Food Processing and Preservation, 40(4), pp. 583-592.

14. Maskan M. (2000), Microwave/air and microwave finish drying of banana. Journal of Food Engineering, 44(2), pp. 71-78.

15. Song X.D., Mujumdar A.S., Law C.L., Fang X.M., Peng W.J., Deng L.Z., Wang J., Xiao H.W. (2020), Effect of drying air temperature on drying kinetics, color, carotenoid content, antioxidant capacity and oxidation of fat for lotus pollen, Drying Technology, 38(9), pp. 1151-1164.

16. Bozkir H., Ergün A.R. (2020), Effect of sonication and osmotic dehydration applications on the hot air drying kinetics and quality of persimmon, LWT-Food Science and Technology, 131, DOI:10.1016/j.lwt.2020.109704

17. Ozcan-Sinir G., Ozkan-Karabacak A., Tamer C.E., Copur O.U. (2018), The effect of hot air, vacuum and microwave drying on drying characteristics, rehydration capacity, color, total phenolic content and antioxidant capacity of kumquat (Citrus japonica), Food Science and Technology, 39(2), pp. 475-484,

18. Karaaslan S.N., Tuncer I.K. (2008), Development of a drying model for combined microwave-fan-assisted convection drying of spinach, Biosystems Engineering, 100(1), pp. 44-52.

19. Zhang M., Tang J., Mujumdar A.S., Wang S., (2006), Trends in microwave-related drying of fruits and vegetables, Trends in Food Science and Technology, 17(10), pp. 524-534. 
20. Arslan A., Soysal Y., Keskin M. (2020), Mathematical modeling, moisture diffusion and color quality in intermittent microwave drying of organic and conventional sweet red peppers, AgriEngineering, 2(3), pp. 393-407.

21. Arikan M. F., Ayhan Z., Soysal Y., Esturk O. (2012), Drying characteristics and quality parameters of microwave-dried grated carrots, Food and Bioprocess Technology, 5(8), pp. 3217-3229.

22. Beaudry C., Raghavan G.S.V., Rennie T.J. (2003), Microwave finish drying of osmotically dehydrated cranberries, Drying Technology, 21(9), pp. 1797-1810.

23. Batista D.d.V.S., Cardoso R.L., Godoy R.C.B.d., Evangelista B.N.S. (2014), Estabilidade físico-química e microbiológica de banana passa orgânica, Ciência Rural, 44(10), pp. 1886 1892.

24. Macedo L.L., Vimercati W.C., Araújo C.d.S., Saraiva S.H., Teixeira L.J.Q. (2020), Effect of drying air temperature on drying kinetics and physicochemical characteristics of dried banana, Journal of Food Process Engineering, 43(9), DOI:10.1111/jfpe.13451

25. Srikanth K.S., Sharanagat V.S., Kumar Y., Bhadra R., Singh L., Nema P. K., Kumar V. (2019), Convective drying and quality attributes of elephant foot yam (Amorphophallus paeoniifolius), LWT-Food Science and Technology, 99, pp. 8-16.

26. Therdthai N., Zhou W.B. (2009), Characterization of microwave vacuum drying and hot air drying of mint leaves (Mentha cordifolia Opizex Fresen), Journal of Food Engineering, 91, pp. 482-489.

27. Liu B., Cao J., Feng A.-G., Liu Y., Yu Q., Li C., Duan Z.-H. (2018), Effects of osmotic dehydration vacuum-microwave drying on the properties of tilapia fillets, Czech Journal of Food Sciences, 36 (2), pp. 169-174.

28. Hawlader M.N.A., Perera C.O., Tian M. (2006), Properties of modified atmosphere heat pump dried foods, Journal of Food Engineering, 74(3), pp. 392-401.

29. Nguyen T.-V.-L., Nguyen Q.-N., Nguyen P.-B.-D., Tran B.-L., Huynh P.-T. (2020), Effects of drying conditions in low-temperature microwave-assisted drying on bioactive compounds and antioxidant activity of dehydrated bitter melon (Momordica charantia L.), Food Science \& Nutrition, 8(7), pp. 3826-3834.

30. Sun Y., Zhang M., Mujumdar A.S., Yu D. (2021), Pulse-spouted microwave freeze drying of raspberry: Control of moisture using ANN model aided by LF-NMR, Journal of Food Engineering, 292, DOI: 10.1016/j.jfoodeng.2020.110354

31. Zhang L., Li P., Wang Z.-G., Shi G.-Y., Wang X.-M., Cheng J.-J., Jiang P.-F., Zhao L.-L., Wang X-Z. (2020), Microwave-vacuum drying kinetics model and quality analysis of Chinese chestnut slice, Modern Food Science and Technology, 36(4), pp. 235-243.

32. Abers J.E., Wrolstad R.E. (1979), Causative factors of color deterioration in strawberry preserves during processing and storage, Journal of Food Science, 44, pp. 75-78. 